\title{
Comentario a la Sentencia del Tribunal Supremo (Sala de lo Contencioso) de 17 de octubre de 2018 (ReCURSO 581/2017): VALIDEZ DE UN ACUERDO DE NO DISPONIBILIDAD DE CRÉDITOS Y OTRAS MEDIDAS POR INCUMPLIMIENTO DEL PLAN DE AJUSTE DEL FLA
}

\section{Comment on the Ruling of the Spanish Supreme Court (Contentious- ADMINISTRATIVE DIVISION) OF OCTOBER 17, 2018 (APPEAL 581/2017): LEGITIMACY OF A NON-AVAILABILITY AGREEMENT ON CREDITS AND OTHER MEASURES DUE TO NONCOMPLIANCE OF THE FLA RULES}

Sergio Luis Doncel Núñez* Trabajo recibido el 29 de agosto de 2019 y aprobado el 4 de diciembre de 2019

\section{Resumen}

La Sentencia resuelve el recurso presentado por la Generalidad de Cataluña contra un Acuerdo de la Comisión Delegada del Gobierno para Asuntos Económicos que adoptó una serie de medidas presupuestarias en el contexto de la intentona separatista en Cataluña en 2017.

Palabras clave: estabilidad presupuestaria, autonomía financiera, acuerdo de no disponibilidad.

\begin{abstract}
The Ruling deals with the appeal interposed by the Catalonian government regarding a Resolution by the Delegated Commission of the Government for Economic Affairs which adopted a number of budgetary measures in the context of the 2017 Catalonian separatist uprising.
\end{abstract}

Keywords: budgetary stability, financial autonomy, non-availability agreement.

\section{INTRODUCCIÓN}

La Sentencia del Tribunal Supremo (Sala de lo Contencioso) de 17 de octubre de 2018, dictada en el recurso 581/2017, desestimó el recurso interpuesto por la Generalidad de Cataluña contra el Acuerdo de

\footnotetext{
Sergio Luis Doncel Núñez. Licenciado en Derecho y Máster en Derecho Público por la Universidad Complutense de Madrid; Máster en Administración Civil del Estado por el Instituto Nacional de Administración Pública y de la Universidad Internacional Menéndez Pelayo (España). Funcionario del Cuerpo Superior de Administradores Civiles del Estado (España). Profesor-tutor de la Universidad Nacional de Educación a Distancia (UNED), España. Correo de contacto: serdoncel@madridsur.uned.es.
} 
la Comisión Delegada del Gobierno para Asuntos Económicos de 15 de septiembre de 2017, por el que se adoptan medidas en defensa del interés general y en garantía de los servicios públicos fundamentales en la Comunidad Autónoma de Cataluña, publicado en el Boletín Oficial del Estado por la Orden HFP/878/2017, de 15 de septiembre.

La Sentencia merece estudio, pues avala que, en el marco del Fondo de Liquidez Autonómico, se pueda adoptar un acuerdo de no disponibilidad sobre créditos presupuestarios de una Comunidad Autónoma (si se dan circunstancias que lo justifiquen), junto con otras medidas que inciden en su autonomía financiera, como el sometimiento a autorización del Consejo de Ministros de las operaciones de endeudamiento, sin necesidad de recurrir al cauce del artículo 155 de la Constitución en los términos establecidos por los artículos 25 y 26.1 de la Ley Orgánica 2/2012.

\section{Consideraciones pRevias}

\subsection{El proceso separatista en Cataluña}

El proceso separatista iniciado en Cataluña en 2012, de funestas consecuencias, ha dado lugar a numerosos frentes. La contienda se desarrolla en el ámbito político, en el penal, en el de las relaciones internacionales... y también en el más técnico pero no menos importante terreno económico-presupuestario: no sólo por los indicios de malversación de caudales públicos por parte de las autoridades catalanas, sino porque, de un tiempo a esta parte, la Generalidad de Cataluña, dada la imposibilidad de financiarse en los mercados por mor de su baja calificación crediticia, se ha visto auxiliada por el Estado central a través del llamado Fondo de Liquidez Autonómico (FLA). Se da entonces la paradoja de que una institución consagrada a la demolición del Estado es financiada por éste.

El empeño por evitar que esos recursos se destinen a fines ilegales se ha materializado en distintas actuaciones, suscitando el máximo interés, habida cuenta del momento crítico en que se aprobó, el Acuerdo de la Comisión Delegada del Gobierno para Asuntos Económicos ${ }^{1}$ de 15 de septiembre de 2017, por el que se adoptan medidas en defensa del interés general y en garantía de los servicios públicos fundamentales en la en la Comunidad Autónoma de Cataluña, publicado en el Boletín Oficial del Estado de fecha 16 de septiembre de 2017 por la Orden HFP/878/2017, de 15 de septiembre.

Ello trae causa del mayor desafío lanzado por el movimiento separatista, que fue la intentona de referéndum de 1 de octubre de 2017, a la que se unió la posterior declaración unilateral de independencia el 27 de octubre de ese mismo año. Hechos que comportaron la intervención de la autonomía catalana, con base en el artículo 155 de la Constitución española (CE)², y la detención y procesamiento de los principales dirigentes políticos que habían participado en lo que, para la Fiscalía del Tribunal Supremo, constituye un golpe de Estado ${ }^{3}$.

1 En España, las Comisiones Delegadas del Gobierno son órganos colegiados del Gobierno -distintos del Consejo de Ministros- que ejercen funciones sobre un área específica de la acción pública que afecta a varios departamentos ministeriales (art. 6 de la Ley 50/1997, de 27 de noviembre, del Gobierno).

2 Mediante el Real Decreto 944/2017, de 27 de octubre, por el que se designa a órganos y autoridades encargados de dar cumplimiento a las medidas dirigidas al Gobierno y la Administración de la Generalitat de Cataluña, autorizadas por acuerdo del Pleno del Senado, de 27 de octubre de 2017, por el que se aprueban las medidas requeridas por el Gobierno, al amparo del artículo 155 de la Constitución.

3 Véase el escrito de conclusiones definitivas, de fecha 29 de mayo de 2019, en la Causa especial 3/20907/2017, pp. 2-5.

DONCEL NúÑEZ, Sergio Luís. Comentario a la Sentencia del Tribunal Supremo (Sala de lo Contencioso) de 17 de octubre de 2018 (recurso 581/2017): Validez de un acuerdo de no disponibilidad de créditos y otras medidas por incumplimiento del plan de ajuste del FLA. Revista Justicia y Derecho, Santiago, v. 2, n², 2019 
Con anterioridad, la STC 90/2017, de 5 de julio, había declarado la inconstitucionalidad y nulidad de la disposición adicional cuadragésima de la Ley de Cataluña 4/2017, de 28 de marzo, de presupuestos de la Generalitat para $2017^{4}$, con el alcance indicado en el fundamento jurídico 12, y que las partidas presupuestarias "GO 01 D/227.0004/132. Procesos electorales y consultas populares", "DD 01 D/227.0004/132. Procesos electorales y consultas populares" y "DD 01 D/227.00157132. Procesos electorales y participación ciudadana" del programa 132 (Organización, gestión y seguimiento de procesos electorales) son inconstitucionales en el caso de que se destinen a la financiación del proceso referendario al que se refiere la disposición adicional cuadragésima de la citada ley.

El Acuerdo citado nace de la voluntad del Gobierno de la nación de impedir que se utilizaran los fondos del FLA para financiar el referéndum declarado inconstitucional. A pesar de su corta vida ${ }^{5}$, es útil examinarlo tanto por la situación extraordinaria y grave a la que respondió como por la sentencia del TS que confirma su legalidad, en la medida en que se pronuncia acerca del alcance que pueden tener medidas derivadas del FLA sobre las Comunidades Autónomas (CCAA).

\subsection{Estabilidad presupuestaria y Comunidades Autónomas}

La financiación autonómica es uno de los problemas insolubles del Estado autonómico español. Las CCAA, sobre todo las más ricas, demandan una mejora de esa financiación para así poder costear con holgura las competencias que han asumido (sanidad, educación, cultura, servicios sociales...). Sin embargo, una mayor atribución de recursos o ingresos a las CCAA supondría que el principio de solidaridad interterritorial quedaría menoscabado, o, cuando menos, que su efectividad dependería de la voluntad de los dirigentes políticos de cada región, no del Estado central.

Por otra parte, a raíz de la crisis económica de 2008, la mayoría de CCAA experimentó importantes desviaciones presupuestarias y un elevado endeudamiento, lo que provocó que se reforzara la tutela del Estado, especialmente tras la reforma constitucional de 2011 que consagró el principio de estabilidad presupuestaria (art. 135 CE) . Al mismo tiempo, el Estado arbitró mecanismos excepcionales para que las CCAA pudieran continuar pagando las nóminas de su personal y los servicios públicos esenciales?.

Jurídicamente, lo anterior se traduce de la siguiente forma. El artículo 156.1 CE reconoce la autonomía financiera de las CCAA "con arreglo a los principios de coordinación con la Hacienda estatal y de solidaridad entre todos los españoles", mientras que el artículo 135.1 CE establece que todas las Administraciones públicas "adecuarán sus actuaciones al principio de estabilidad presupuestaria". El principio de estabilidad presupuestaria opera como límite a la autonomía financiera (STC 134/2011, de 20 de julio).

El artículo 135 CE ha sido objeto de desarrollo por la Ley Orgánica 2/2012, de 27 de abril, de Estabilidad Presupuestaria y Sostenibilidad Financiera, que regula tanto la definición e instrumentación de

4 El precepto recurrido emplazaba al Gobierno de la Generalidad a habilitar los recursos necesarios en materia de organización y gestión para hacer frente al denominado proceso referendario sobre el futuro político de Cataluña.

5 Fue derogado por el Acuerdo de la Comisión Delegada del Gobierno para Asuntos Económicos de 21 de diciembre de 2017 , por el que se adoptan medidas en defensa del interés general y en garantía de los servicios públicos fundamentales en la Comunidad Autónoma de Cataluña, en ejecución de la resolución del Senado de 27 de octubre de 2017, publicado en el BOE por Orden HFP/1281/2017, de 22 de diciembre.

6 Para una explicación de todo el proceso, sus detalles y las distintas posturas doctrinales, véase Esparza (2012).

7 Entre ellos, el Fondo de Liquidez Autonómico (FLA). Creado por el Real Decreto-ley 21/2012, de 13 de julio, de medidas de liquidez de las Administraciones públicas y en el ámbito financiero, se define en su artículo 1 como un "mecanismo de apoyo a la liquidez de las Comunidades Autónomas, de carácter temporal y voluntario, que permita atender las necesidades financieras", sujeto a condiciones. La actual regulación del FLA se contiene en el Real Decreto-ley 17/2014, de 26 de diciembre, de medidas de sostenibilidad financiera de las comunidades autónomas y entidades locales y otras de carácter económico.

DONCEL NÚÑEZ, Sergio Luís. Comentario a la Sentencia del Tribunal Supremo (Sala de lo Contencioso) de 17 de octubre de 2018 (recurso 581/2017): Validez de un acuerdo de no disponibilidad de créditos y otras medidas por incumplimiento del plan de ajuste del FLA. Revista Justicia y Derecho, Santiago, v. 2, n², 2019 
los principios aludidos como una serie de medidas preventivas, correctivas y coercitivas encaminadas a garantizar su cumplimiento.

La LO 2/2012 prevé en su disposición adicional primera que aquellas CCAA y corporaciones locales que soliciten al Estado el acceso a mecanismos de financiación, como el FLA, "vendrán obligadas a acordar con el Ministerio de Hacienda y Administraciones Públicas un plan de ajuste, cuando sea preceptivo, que sea consistente con el cumplimiento de los objetivos de estabilidad presupuestaria y de deuda pública". De este modo, se comprende que la financiación estatal, más accesible y ventajosa que la que proporcionan los mercados, viene ineludiblemente acompañada de medidas para cumplir los objetivos de déficit y endeudamiento, fijados conforme a la LO 2/2012.

En la actualidad, esos mecanismos aparecen regulados por el Real Decreto-ley 17/2014, de 26 de diciembre, de medidas de sostenibilidad financiera de las comunidades autónomas y entidades locales y otras de carácter económico, en cuyo preámbulo se lee lo siguiente:

"En el marco de esta disposición, son varios los mecanismos que desde el año 2012 el Estado ha puesto en marcha, como son el Fondo para la financiación de los pagos a proveedores, el Fondo de liquidez autonómico o las medidas extraordinarias de apoyo a municipios con problemas financieros. Todos ellos con el objetivo común de aportar liquidez tanto a las Comunidades Autónomas como a las Entidades Locales para que pudieran hacer frente a sus obligaciones de pago en un momento de dificultad económica a cambio del cumplimiento de un conjunto de condiciones fiscales y financieras que han ayudado a que puedan ir cumpliendo con los objetivos de consolidación fiscal y garantizar la sostenibilidad de las cuentas públicas".

Cataluña se adhirió al FLA en $2012^{8}$.

\section{El Acuerdo de la Comisión Delegada del Gobierno para Asuntos Económicos DE 15 DE SEPTIEMBRE DE 2017, POR EL QUE SE ADOPTAN MEDIDAS EN DEFENSA DEL INTERÉS GENERAL Y EN GARANTÍA DE LOS SERVICIOS PÚBLICOS FUNDAMENTALES EN LA Comunidad Autónoma de Cataluña}

Por lo pronto, hay que acotar los hechos más específicos que motivaron la adopción del Acuerdo impugnado. La propia resolución dedica a esta tarea un largo espacio, en su Exposición, debiendo destacarse, ante todo, que las actuaciones en cuestión

"han sido de diferente índole y en particular, dieron lugar a que el día 5 de julio de 2017 se dictara sentencia del Tribunal Constitucional por el que se declaró la inconstitucionalidad y nulidad de la disposición adicional 40 de la Ley del Parlamento de Cataluña 4/2017, de 28 de marzo, de Presupuestos de la Generalitat para 2017y de determinadas partidas presupuestarias de los mismos. Esta situación, añadida a las diferentes actuaciones de representantes y miembros de instituciones públicas y sus efectos sobre la financiación y el acceso a los mercados por parte de la Administración de Cataluña ha dado lugar a que en este tiempo se hayan ido adoptando, de forma progresiva, diferentes medidas, para garantizar la estabilidad presupuestaria, la sostenibilidad financiera y los servicios públicos esenciales".

8 Así lo expone Calvo (2011), p. 103:"Con fecha 28 de agosto de 2012 la Comunidad Autónoma de Cataluña solicitó al Ejecutivo adherirse al Fondo de Liquidez Autonómico mediante la concesión de un préstamo por importe de 5.023 millones de euros. No obstante, con fecha 30 de octubre de ese mismo año se conoció que la cifra definitiva del rescate ascendía a 5.370 millones de euros. El Ejecutivo catalán pagaría un interés próximo al 5,65\% por las transferencias del FLA, abonando 300 millones de euros entre 2013 y 2014 (periodo de carencia en que sólo afrontaría intereses) y amortizando unos 679 millones entre 2015 y 2022, además de pagar los intereses correspondientes".

DONCEL NÚÑEZ, Sergio Luís. Comentario a la Sentencia del Tribunal Supremo (Sala de lo Contencioso) de 17 de octubre de 2018 (recurso 581/2017): Validez de un acuerdo de no disponibilidad de créditos y otras medidas por incumplimiento del plan de ajuste del FLA. Revista Justicia y Derecho, Santiago, v. 2, n², 2019 
Se explica que se adoptaron medidas para que autoridades y funcionarios de la Generalidad remitieran certificados periódicos semanales "para acreditar que no se han iniciado o tramitado modificaciones presupuestarias ni expedientes de gastos o pagos, presupuestarios o extrapresupuestarios, en sus respectivos ámbitos de competencia", que puedan dedicarse a actividades relacionadas con el referéndum declarado inconstitucional por la STC 90/2017.

Es en este momento cuando la situación se agrava todavía más y se acerca la fecha para la celebración del tristemente famoso referéndum, el 1 de octubre de 2017, y se comunica al Ministerio de Hacienda la intención de incumplir la obligación de remitir los certificados, al considerarlos contrarios a la normativa reguladora del referéndum, aprobada por el Parlamento catalán?.

Así las cosas, en el Acuerdo impugnado se contemplaba la adopción por parte del Presidente de la Comunidad Autónoma de Cataluña de un acuerdo de no disponibilidad (al objeto de asegurar el equilibrio presupuestario) sobre todos los créditos presupuestarios distintos a los previstos en los anexos I y Il del Acuerdo de la Comisión Delegada del Gobierno para Asuntos Económicos de 20 de noviembre de 2015; subsidiariamente, se preveía que fuese adoptado por el Ministro de Hacienda (apartado primero) ${ }^{10}$.

Por otra parte, para los pagos con cargo a los créditos de los referidos anexos I y II, se establece un sistema de certificaciones que garantice que "no se financia ninguna actividad no amparada por la ley, ni contraria a las decisiones de los tribunales".

Conviene destacar, llegados a este punto, que estas medidas tienen por finalidad "evitar que se financien actividades contrarias al ordenamiento jurídico vigente y asegurar que la financiación que tiene como origen la Hacienda del Estado, se destina al pago de los sueldos y salarios de los empleados públicos, la sanidad, la educación y los servicios sociales, como servicios públicos fundamentales" (apartado segundo).

En cuanto al endeudamiento, todas las operaciones de endeudamiento de la Comunidad Autónoma de Cataluña requerirían autorización del Consejo de Ministros (apartado cuarto).

La vigencia de estas medidas se extendería, según el apartado octavo, hasta que desapareciera la situación de riesgo para el interés general en la Comunidad Autónoma de Cataluña o fuese necesario para garantizar la prestación de los servicios públicos en la Comunidad Autónoma, a juicio de la Comisión Delegada del Gobierno para Asuntos Económicos.

La fundamentación del Acuerdo, en fin, procede de principios de rango constitucional, como la estabilidad presupuestaria y la coordinación, de su desarrollo en la LO 2/2012, invocando al respecto los principios de responsabilidad (art. 8), lealtad institucional (art. 9) y la disposición adicional primera, y del Real Decreto-ley 17/2014.

9 Ley 19/2017, de 6 de septiembre, del referéndum de autodeterminación, y Ley 20/2017, de 8 de septiembre, de transitoriedad jurídica y fundacional de la República. Tales normas, que pretendían una total ruptura del orden constitucional, se hallaban a la sazón suspendidas al haber sido impugnadas ante el Tribunal Constitucional por el Gobierno y fueron declaradas inconstitucionales y nulas por las SSTC 114/2017, de 17 de octubre, y 124/2017, de 8 de noviembre, respectivamente.

10 Es lo que finalmente ocurrió, con arreglo a la Orden HPF/886/2017, de 20 de septiembre, por la que se declara la no disponibilidad de créditos en el Presupuesto de la Comunidad Autónoma de Cataluña para el 2017. El recurso de la Generalidad contra dicha Orden fue desestimado por la STS de 23 de octubre de 2018 (recurso 594/2017). 


\section{LA STS DE 17 dE OCTUBRE DE 2018}

\subsection{Motivos de impugnación alegados}

La Generalidad basa su recurso en motivos de carácter de carácter procedimental. En primer lugar, alega que el acuerdo de no disponibilidad es nulo, ya que no se ha seguido el procedimiento previsto en la LO 2/2012, concretamente en los artículos 25 y 26, y no es posible, adicionalmente, que el Ministro de Hacienda pueda acordarlo, según dispone el Acuerdo recurrido, porque no está previsto en la LO 2/2012.

En segundo lugar, se aduce como motivo de nulidad que se ha prescindido total y absolutamente del procedimiento legalmente establecido. En opinión de la Generalidad, para la adopción del Acuerdo se ha omitido el procedimiento; en este sentido, no hay informes o documentos en el expediente que justifiquen su necesidad.

Por último, se considera que el Acuerdo carece de motivación y que sus medidas son desproporcionadas. Respecto a la ausencia de motivación, no se explica la relación de las medidas con los objetivos de estabilidad presupuestaria y sostenibilidad financiera. Sobre la infracción del principio de proporcionalidad, sostiene que exceden de los límites del FLA y son inidóneas para la finalidad perseguida.

Aquí se reitera la principal controversia que se dirime en la Sentencia, y es que, para la Generalidad, medidas de esa índole pasan necesariamente por aplicar el artículo 155 CE, en los términos expresados en el artículo 26.1 LO 2/2012:

"En el supuesto de que una Comunidad Autónoma no adoptase el acuerdo de no disponibilidad de créditos previsto en el artículo 25.1.a), no constituyese el depósito obligatorio establecido en el artículo 25.1.b) o no implementase las medidas propuestas por la comisión de expertos prevista en el artículo 25.2, el Gobierno, de conformidad con lo dispuesto en el artículo 155 de la Constitución Española, requerirá al Presidente de la Comunidad Autónoma para que lleve a cabo, en el plazo que se indique al efecto, la adopción de un acuerdo de no disponibilidad, la constitución del depósito obligatorio establecido en el artículo 25.1.b) o la ejecución de las medidas propuestas por la comisión de expertos.

En caso de no atenderse el requerimiento, el Gobierno, con la aprobación por mayoría absoluta del Senado, adoptará las medidas necesarias para obligar a la Comunidad Autónoma a su ejecución forzosa. Para la ejecución de las medidas el Gobierno podrá dar instrucciones a todas las autoridades de la Comunidad Autónoma."

Entender otra cosa, según la Generalidad, convertiría al FLA en un instrumento que incide en la autonomía financiera de las CCAA y, en consecuencia, en sus competencias. Por lo tanto, la única vía debería ser la del artículo 155 CE, que exige el requerimiento previo al Presidente de la Comunidad Autónoma y, en su caso, la adopción de las medidas necesarias, previa aprobación de la mayoría absoluta del Senado.

\subsection{La decisión del Tribunal Supremo}

Se analizan a continuación los razonamientos que llevan al TS a desestimar los motivos esgrimidos por la Generalidad.

Con relación al procedimiento necesario para adoptar el Acuerdo, la Sentencia recuerda que el referéndum previsto para el 1 de octubre de 2017 había sido declarado inconstitucional y que, por ende, era ilícito destinar partidas presupuestarias a financiarlo:

DONCEL NÚÑEZ, Sergio Luís. Comentario a la Sentencia del Tribunal Supremo (Sala de lo Contencioso) de 17 de octubre de 2018 (recurso 581/2017): Validez de un acuerdo de no disponibilidad de créditos y otras medidas por incumplimiento del plan de ajuste del FLA. Revista Justicia y Derecho, Santiago, v. 2, n² 2, 2019 
"Aparece, como destaca el Abogado del Estado, una vocación y voluntad proclamada del Gobierno de la Generalidad de gastar dinero público para organizar un referéndum inconstitucional. Esa vocación precisa de recursos públicos que se van a allegar desde la habilitación presupuestaria cuestionada en este recurso y declarada inconstitucional por la sentencia de 5 de julio de 2017. Y esos recursos públicos se obtienen a través de mecanismos de financiación externa como son los fondos dotados a la Generalidad como parte integrante del FLA, fondos que, obviamente, no pueden ser dispuestos para conseguir un fin inconstitucional."

El TS razona que la Comunidad recurrente está vinculada por sus propios actos: si se adhirió al FLA, debe ahora respetar las condiciones a él anudadas y, particularmente, no puede destinar los fondos obtenidos" a financiar procesos declarados inconstitucionales con quebranto de los servicios públicos a que se debe e incumplimiento el principio de competencia al que se vincula su autonomía financiera".

Así, el Alto Tribunal, tras señalar que la Generalidad se ha adherido al FLA"con todas sus consecuencias", concluye que el origen del Acuerdo impugnado radica en el incumplimiento de las reglas de aquél y del principio de estabilidad presupuestaria. No es necesario, pues, aplicar el artículo 155 CE: la disposición adicional primera de la LO 2/2012 es cobertura suficiente para el acuerdo de no disponibilidad, así como la regulación del Real Decreto-ley 17/2014, cuyo artículo 22.3 establece lo siguiente:

"Aceptada la solicitud, la Comunidad Autónoma adoptará un Acuerdo de su Consejo de Gobierno u órgano competente, en el que conste su voluntad de adhesión a este compartimento y el compromiso de cumplir lo dispuesto en este real decreto-ley, los Acuerdos del Consejo de Política Fiscal y Financiera, los Acuerdos de la Comisión Delegada del Gobierno para Asuntos Económicos, en el Programa que resulte de aplicación, así como lo previsto en cualquier disposición que desarrolle este mecanismo de financiación".

Por ello, como asevera la Sentencia, es "un compromiso voluntario cuyas consecuencias se expresan legalmente de modo que la Comunidad Autónoma queda sujeta a las decisiones y disposiciones mencionadas". Y la Comisión Delegada del Gobierno para Asuntos Económicos puede adoptar acuerdos sobre esa base, como ha ocurrido en el presente caso.

Contrariamente a lo que pretende la Generalidad, no se da la situación descrita en el artículo 25 LO 2/2012, ni el acuerdo de no disponibilidad exige acudir al artículo 155 CE:

"La aplicación a los artículos 25 y 26 LOEP se basa en que, mediante el procedimiento previsto en dichos artículos y la aplicación del artículo 155 de la Constitución se podrá adoptar, entre otras medidas, el acuerdo de no disponibilidad de créditos. Sin embargo, en ninguno de esos preceptos se prohíbe que se adopte dicha decisión cuando la Comunidad percibe fondos del FLA y manifiesta que no los destinará a los fines para los que se dotan. Se requiere aquí a la Comunidad Autónoma, mediante un acuerdo adoptado por el órgano competente habilitado legalmente para que garantice el respeto a la estabilidad presupuestaria y para eso no es necesario utilizar un mecanismo tan extremo como el recogido en el artículo 155 de la Constitución".

También rechaza el TS que se haya omitido total y absolutamente el procedimiento legalmente establecido, toda vez que el Acuerdo se enmarca en la regulación de la estabilidad presupuestaria, que viene conformada por la LO 2/2012 y el Real Decreto-ley 17/2014. El pronunciamiento del TS es rotundo:

"Las normas reguladoras de la estabilidad presupuestaria habilitan a la Comisión Delegada del Gobierno para Asuntos Económicos para adoptar acuerdos en esta materia y dicha adopción no precisa de procedimiento administrativo específico más allá de la remisión del mismo a dicha Comisión, inclusión en el orden del día y aprobación en la forma legalmente establecida".

Por lo que se refiere a la alegada falta de motivación, la Sentencia declara que basta con examinar la Exposición del Acuerdo recurrido para comprobar que cuenta con motivación suficiente.

DONCEL NúÑEZ, Sergio Luís. Comentario a la Sentencia del Tribunal Supremo (Sala de lo Contencioso) de 17 de octubre de 2018 (recurso 581/2017): Validez de un acuerdo de no disponibilidad de créditos y otras medidas por incumplimiento del plan de ajuste del FLA. Revista Justicia y Derecho, Santiago, v. 2, n², 2019 
Asimismo, las medidas son proporcionadas. La finalidad de las mismas no es otra que garantizar que los fondos recibidos del FLA"se destinan a satisfacer fines legal y presupuestariamente exigidos en lugar de destinarse a la financiación de fines declarados constitucionales, en demérito de los servicios públicos a cuya satisfacción se deben los poderes públicos". Las medidas son coherentes con ese objetivo y no suponen una intromisión ilegítima en las competencias autonómicas.

\section{Comentarios}

La Sentencia analizada presenta como conclusión más relevante que el propio FLA "ampara mecanismos de control y consecuencias caso de incumplimiento de sus obligaciones" y que el control y garantía de que los fondos obtenidos se apliquen a los fines presupuestarios, cuando se ha incumplido el plan de ajuste, "no tiene por qué seguir el cauce del artículo 26 para el caso de incumplimiento de lo previsto en su primer apartado y del artículo 155 de la Constitución"11.

En suma, es un espaldarazo a la actuación del Estado en este supuesto y viene a fortalecer una interpretación rigurosa de los compromisos asumidos por las CCAA a resultas de su adhesión al FLA -frente a quienes consideran que el Estado debe facilitar la financiación casi a fondo perdido-, si bien es cierto que el Acuerdo impugnado no puede desligarse de una situación de carácter extraordinario que no es en absoluto la habitual en las relaciones Estado-CCAA.

La Sentencia, por otra parte, contiene afirmaciones valiosas sobre la doctrina de los actos propios aplicada a las Administraciones Públicas y el principio de proporcionalidad.

Como ha podido verse, el entramado es complejo. Incluso algo que, en principio, es meridianamente claro en un Estado de Derecho (que los recursos públicos no pueden destinarse a la comisión de ilegalidades) requiere para su implementación de un Acuerdo muy bien fundado. Con todo, la Generalidad lo impugnó ante la jurisdicción contenciosa, lo que no deja de ser sorprendente, si se atienden a las declaraciones de muchos de sus mandatarios en 2017, dedicados a la tarea de desconectar Cataluña de España y para los que el Estado español actual -dentro del cual se hallan instituciones como el TS- se diferencia poco del Estado franquista.

A mi juicio, a fin de que la estabilidad presupuestaria sea un principio serio, respetado, es esencial un papel fuerte del Estado ${ }^{12}$ : la centralización es aquí una opción perfectamente racional ${ }^{13}$. Asimismo, en tanto mecanismos como el FLA sigan existiendo, es obvio que el Estado dispondrá de mayores instrumentos de control y las CCAA, sin perjuicio de su autonomía financiera, lo han de aceptar.

11 Carrasco (2013), p. 202, manifiesta su contrariedad ante el hecho de que, en vez de utilizar los mecanismos previstos en la LO 2/2012, el Estado emplea "Ios controles inherentes al Fondo de Liquidez Autonómica como una vía más eficaz para supervisar la marcha de las finanzas de las Comunidades Autónomas". Pero no puede soslayarse que las CCAA se unen a dicho fondo voluntariamente, sometiéndose a la imprescindible supervisión, y que el FLA ha estado vinculado ab initio a la estabilidad presupuestaria. No es admisible, en definitiva, que una región cuyas finanzas se sostienen gracias a ese mecanismo no adopte ningún ajuste que le permita corregir los desequilibrios.

12 De acuerdo con Esparza (2012), p. 166, en un Estado descentralizado, con múltiples centros de gasto, es necesaria una coordinación general en manos del Estado, como sujeto "constitucionalmente preeminente".

13 Como observan García y Salinas (1997), pp. 569-570, la organización fiscal centralizada es más eficaz para alcanzar el objetivo de estabilización de la economía con carácter general, desaconsejando la descentralización de la política fiscal y monetaria.

DONCEL NÚÑEZ, Sergio Luís. Comentario a la Sentencia del Tribunal Supremo (Sala de lo Contencioso) de 17 de octubre de 2018 (recurso 581/2017): Validez de un acuerdo de no disponibilidad de créditos y otras medidas por incumplimiento del plan de ajuste del FLA. Revista Justicia y Derecho, Santiago, v. 2, n² 2, 2019 


\section{Bibliografía Citada}

Calvo Vérgez, Juan (2011): "La crisis financiera de las Comunidades Autónomas y la creación del fondo de liquidez autonómico como mecanismo destinado a hacer frente a las dificultades de acceso a la financiación", Revista de estudios de la Administración local y autonómica, № 317: pp. 73-112.

Carrasco Durán, Manuel (2013): "Estabilidad presupuestaria y Comunidades Autónomas", Revista d'estudis autonòmics i federals, № 18: pp. 169-2016.

Esparza Oroz, Miguel (2012): "El nuevo marco de la estabilidad presupuestaria en España”, Asamblea: revista parlamentaria de la Asamblea de Madrid, № 26: pp. 153-202.

García Villarejo, Avelino y Salinas Sánchez, Javier (1997): Manuel de Hacienda Pública general y de España (Madrid, Tecnos).

Lasarte Álvarez, Francisco Javier (1979): "La financiación de las Comunidades Autónomas", Revista de estudios regionales, № extra 4: pp. 475-501.

\section{NORMAS CITADAS}

Constitución española de 1978.

Ley Orgánica 2/2012, de 27 de abril, de Estabilidad Presupuestaria y Sostenibilidad Financiera.

Real Decreto-ley 21/2012, de 13 de julio, de medidas de liquidez de las Administraciones públicas y en el ámbito financiero.

Real Decreto-ley 17/2014, de 26 de diciembre, de medidas de sostenibilidad financiera de las comunidades autónomas y entidades locales y otras de carácter económico.

Ley de Cataluña 4/2017, de 28 de marzo, de presupuestos de la Generalitat para 2017.

\section{JURISPRUDENCIA CITADA}

STC 134/2011, de 20 de julio.

STC 90/2017, de 5 de julio.

STS (Sala de lo Contencioso) de 17 de octubre de 2018.

STS (Sala de lo Contencioso) de 23 de octubre de 2018.

DONCEL NÚÑEZ, Sergio Luís. Comentario a la Sentencia del Tribunal Supremo (Sala de lo Contencioso) de 17 de octubre de 2018 (recurso 581/2017): Validez de un acuerdo de no disponibilidad de créditos y otras medidas por incumplimiento del plan de ajuste del FLA. Revista Justicia y Derecho, Santiago, v. 2, n², 2019 